\title{
Assessment of atrial septal defects rims on transesophageal echocardiogram at Shahid Gangalal National Heart Centre, Kathmandu, Nepal
}

\author{
Chandra Mani Adhikari, ${ }^{1}$ Manish Shrestha, ${ }^{2}$ Urmila Shakya ${ }^{2}$ \\ I Department of Cardiology, Shahid Gangalal National Heart Centre, Kathmandu, Nepal \\ 2 Department of Pediatric Cardiology, Shahid Gangalal national Heart Centre, Kathmandu, Nepal
}

Corresponding author: Chandra Mani Adhikari,

Department of Cardiology

Shahid Gangalal National Heart Centre, Kathmandu, Nepal

Email address: topjhap@gmail.com

\section{Abstract}

\begin{abstract}
Background and Aims: Transcatheter Atrial septal defects (ASD) closure has become the better alternative to surgical closure. Morphological variations of ASD are frequent. We aim to study the rims of ASD in Transesophageal echocardiogram (TEE).

Methods: It was a retrospective single center audit done at Shahid Gangalal National Heart Centre, Kathmandu, Nepal. TEE clips of all the patients who underwent TEE evaluation for ASD device closure in our centre between June to August 2017 were studied.

Results: During the study period 49 patients underwent TEE to evaluate the rims of ASD for device closure. Atrioventricular rim was good in all patients but it was floppy in one patient. In four chamber view, posterior rim was good in $21(42.8 \%)$ patients, floppy in $19(38.7 \%)$ patients and absent in nine (18.5\%) patients. Aortic rim was good in $15(30.6 \%)$ patients, floppy in three $(6.1 \%)$ patients and absent in 31(63.3\%) patients. Posterior rim in short axis was good in $17(34.6 \%)$ patients, floppy in $24(48.9 \%)$ patients while it was absent in eight (16.3\%) patients. Inferior venacava rim was good in $16(32.6 \%)$ patients, floppy in $23(46.9 \%)$ patients, while absent in ten (20.4\%) patients. Superior venacava rim was good in $45(91.8 \%)$ patients, floppy in one $(2.1 \%)$ patient and absent in three $(6.1 \%)$ patients. Two $(4.1 \%)$ patients had two ASDs.
\end{abstract}

Conclusion: Most of the ASD patients have absent rims which makes the procedure more demanding and challenging.

Key words: Atrial septal defect; rims; transcatheter closure; transesophageal echocardiogram.

DOI: http://dx.doi.org/10.3126/njh.v14i2.18501

\section{Introduction}

Transcatheter Atrial septal defects (ASD) closure has become the treatment of choice in many institutions. ${ }^{1}$ Morphological variations of secundum-type ASD are common and their recognition is crucial for selection of patients suitability for percutaneous closure. ${ }^{2}$ Transesophageal echocardiogram (TEE) remains the gold standard for ASD closure. ${ }^{3}$ TEE assessment of ASD includes evaluation of the number and localization of the defect(s), dimensions and adequacy of the rims. ${ }^{4}$

An audit was done to study the rims of ASD in patients with ASD secundum who were evaluated with TEE.

\section{Methods}

It was a retrospective single center audit done at Shahid Gangalal National Heart Centre, Kathmandu, Nepal. TEE clips of all the patients who underwent TEE evaluation for ASD device closure in echolab of our centre between June to August 2017 were reviewed by three operators to evaluate the rims of ASD. Atrioventricular (AV) rim and posterior rim in four chamber view, aortic and posterior rim in short axis view and Inferior venacava (IVC) and Superior venacava (SVC) rims in bicaval view were measured and documented. Views used for assessment of ASD by TEE were as per the Guidelines for the Echocardiographic Assessment of Atrial Septal Defect and Patent Foramen Ovale: From the American Society of Echocardiography and Society for Cardiac Angiography and Interventions. ${ }^{5}$

Rims measurement were done as per T Podnar et al, ${ }^{2}$

1) The superior anterior rim was measured in the transverse view in the plane of the aortic valve, as the minimal distance from the anterior margin of the defect to the aortic wall.

2) In the four-chamber view, the minimal distance between the margin of the defect and atrioventricular valves was measured-the inferior anterior rim.

3) The posterior rim was measured in the transverse view in the plane of the central atrial septum or in the four-chamber view. The posterior rim was measured from the posterior margin of the defect to the posterior atrial wall.

4) Longitudinal view in the plane of the caval veins was used for the measurement of the superior posterior rim and the inferior posterior rim. The former was measured from the superior defect margin to the opening of the superior vena cava and the latter from the inferior margin of the defect to the opening of the inferior vena cava.

Rim more than or equal to $5 \mathrm{~mm}$ was considered 'good' and rim was defined 'absent' if the rim was less than $5 \mathrm{~mm}$. Floppy rim was defined as if it moves back and forth with blood flow and flutters. Number of defects were recorded if there were presence of more than one ASD. The study protocol was approved by the institutional review committee of the Shahid Gangalal National Heart Centre.

@Nepalese Heart Journal. Nepalese Heart Journal retains copyright and work is simultaneously licensed under Creative Commons Attribution License CC - BY 4.0 that allows others to share the work with an acknowledgement of the work's authorship and initial publication in this journal. 


\section{Results}

During the study period 49 patients underwent TEE evaluation for ASD device closure. Most of them were female, 31 (63\%) were female and $18(37 \%)$ were male. Age ranged between 15 to 60 years with the mean age of 33.6 years.

$\mathrm{AV}$ rim was good in all patients but floppy in one patient. In four chamber view, posterior rim was good in $21(42.8 \%)$ patients, floppy in $19(38.7 \%)$ patients and absent in nine (18.5\%) patients. Aortic rim was good in $15(30.6 \%)$ patients, floppy in three $(6.1 \%)$ patients and absent in 31(63.3\%) patients. Posterior rim in short axis was good in 17 (34.6\%) patients, floppy in 24 (48.9\%) patients while it was absent in $8(16.3 \%)$ patients. IVC rim was good in 16 $(32.6 \%)$ patients, floppy in $23(46.9 \%)$ patients and absent in ten (20.4\%) patients. SVC rim was good in 45 (91.8\%) patients, floppy in one $(2.1 \%)$ patient while it was absent in three $(6.1 \%)$ patients (Table 1). Two (4.1\%) patients had two ASDs. All rims are present in 7 patients, among them only two patients $(4.1 \%)$ patients had good all rims while other five patients had floppy rims.

\begin{tabular}{llll}
\multicolumn{2}{l}{ Table 1: Rims of ASD } & & \\
& $\begin{array}{l}\text { Good Rim } \\
\mathrm{n}(\%)\end{array}$ & $\begin{array}{l}\text { Floppy rim } \\
\mathrm{n}(\%)\end{array}$ & $\begin{array}{l}\text { Absent rim } \\
\mathrm{n}(\%)\end{array}$ \\
\hline $\mathrm{AV}$ & $48(97.9)$ & $1(2.1)$ & 0 \\
\hline $\begin{array}{l}\text { Posterior (four } \\
\text { chamber view) }\end{array}$ & $21(42.8)$ & $19(38.7)$ & $9(18.5)$ \\
\hline $\begin{array}{l}\text { Aortic } \\
\text { Posterior (short } \\
\text { axis view) }\end{array}$ & $15(30.6)$ & $3(6.1)$ & $31(63.3)$ \\
IVC & $16(32.6)$ & $24(48.9)$ & $8(16.3)$ \\
SVC & $45(91.8)$ & $1(2.1)$ & $3(6.1)$
\end{tabular}

\section{Discussion}

Though a small single centre study, it provides information about the rims of ASD in Nepalese patients. It is well known that morphological variations of ASD are frequent and appropriate patient selection for transcatheter ASD closure is crucial for successful procedure. ${ }^{1}$

In our study four percentage of patients had more than one ASD. The presence of multiple defects of the inter-atrial septum have been reported between $5.3 \%$ to $7.3 \%$ of patients with ostium secundum ASD. ${ }^{2,6,7}$

In our study Aortic rim was absent in $63.3 \%$ patients, it is the rim which is most commonly absent in ASD secundum patients. Though absent Aortic rim is not a contraindication for device closure, its absence makes device closure procedure complex. When Podnar et al, ${ }^{2}$ defined 10 morphological variations of defects, the most common type being the defect with deficient aortic rim, which was absent in $42.1 \%$. In other studies also it was the most commonly absent rim in $49.3 \%{ }^{6}$ patients and in $53 \%^{7}$ patients. Pillaai ${ }^{6}$ et al considered that deficient aortic rim is a rather common morphologic feature of ASD and is present in up to $30-50 \%$ of ASDs that are considered complex. If $5 \mathrm{~mm}$ is considered to be an adequate rim size, then aortic rim deficiency will be common because more than $40 \%$ of patients with ASD have an aortic rim that is $<5 \mathrm{~mm} .^{2}$

Deficient aortic rim has been associated with increased risk of device impingement on the aorta. ${ }^{8}$ Ostermayer et al. found that small aortic rim is independently associated with procedural failure. ${ }^{9}$ On the other hand, O'Byrne et al. found that deficient aortic rim is highly prevalent but does not seem to increase the risk of adverse outcomes. ${ }^{10}$ Another group found that procedural failure mainly occurs with extremely large defects $(\geq 40 \mathrm{~mm})$, regardless of whether an aortic rim of septal tissue was present. ${ }^{11}$

Deficient or floppy posterior rims are the second most common variation in ASD rims. Deficient/floppy posterior rim was present in $30.6 \%$ patients. $^{6}$ IVC rim is the most important rim for ASD device closure, absence of IVC rim is considered contraindication for Device therapy. IVC rim was absent in $20 \%$ patients and floppy in $47 \%$ patients. In a study done by Podnar et al. ${ }^{2}$ it was absent in only $12 \%$ patients. In our study good SVC and $\mathrm{AV}$ rim was present in most of the patients. In a study done by Podnar et al. ${ }^{2}$ SVC rim was absent in only $1 \%$ patients.

Small, single centre, retrospective audit is the major limitation of our study.

\section{Conclusion}

Most of the ASD patients have absent rims, which makes the procedure more demanding and challenging. Further prospective, large study is needed to describe the character of rims of ASD in Nepalese population.

\section{References}

1. Teiji Akagi. Current concept of transcatheter closure of atrial septal defect in adults. Journal of Cardiology 2015;65:17-25. https://doi.org/10.1016/j.jjcc.2014.09.002

2. Tomaz Podnar, Peter Martanovič , Pavol Gavora, et al. Morphological Variations of Secundum-Type Atrial Septal Defects: Feasibility for Percutaneous Closure Using Amplatzer Septal Occluders. Cathet

Cardiovasc Intervent 2001;53:386-391. https://doi. org/10.1002/ccd.1187

3. Yolandee Bell-Cheddar, Zahid Amin. Indication and Evaluation for ASD closure. Cardiac Interventions today 2011.48-52.

4. Ayax Sobrino, Arsène J. Basmadjian,Anique Ducharme, et al. Multiplanar transesophageal echocardiography for the evaluation and percutaneous management of ostium secundum atrial septal defects in the adult. Arch Cardiol Mex 2012;82(1):37-47

5. Guidelines for the Echocardiographic Assessment of Atrial Septal Defect and Patent Foramen Ovale: From the American Society of Echocardiography and Society for Cardiac Angiography and Interventions. J Am Soc Echocardiogr 2015; 28:910-58. https://doi.org/10.1016/j. echo.2015.05.015

6. Pillai AA, Satheesh S, Pakkirisamy G, et al. Techniques and outcomes of transcatheter closure of complex atrial septal defects - single center experience. Indian Heart J. 2014;66:38-44. https://doi.org/10.1016/j.ihj.2013.12.016

7. Ali S.H. et al.,Short-term outcomes of transcatheter closure of secundum atrial septal defect in children and adolescents: An experience of two centers in Upper Egypt. J Saudi Heart Assoc (2017), http://dx.doi.org/10.1016/j.jsha.2017.04.004. https://doi.org/10.1016/j.jsha.2017.04.004

8. Tal R, Dotan M, Schwartz Y, et al. Challenges in Atrial Septal Defect Occlusion. Structural Heart Disease. 2017;3(1):1527. https://doi.org/10.12945/j.jshd.2016.005.16

9. Ostermayer SH, Srivastava S, Doucette JT, et al. Malattached septum primum and deficient septal rim predict unsuccessful transcatheterclosure of atrial communications. Catheter Cardiovasc Interv. 2015;86:1195-1203. https://doi. org/10.1002/ccd.26102

10. O’Byrne ML, Glatz AC, Sunderji S, et al. Prevalence of deficient retro-aortic rim and its effects on outcomes in device closure of atrial septal defects. Pediatr Cardiol. 2014;35:1181-1190. https://doi.org/10.1007/s00246-014-0914-6

11. Romanelli G, Harper RW, Mottram PM. Transcatheter closure of secundum atrialseptal defects: results in patients with large and extreme defects. Heart Lung Circ. 2014;23:127-131. https://doi.org/10.1016/j.hlc.2013.07.020

Cite this article as: Chandra Mani Adhikari,Assessment of atrial septal defects rims on transesophageal echocardiogram at Shahid Gangalal National Heart Centre, Kathmandu, Nepal. Nepalese Heart Journal 2017; 14(2): 35-36. http://dx.doi.org/10.3126/njh.v14i2.18501 